\title{
Controlling Friction and Wear with Anisotropic Microstructures in MoN-Coated Surfaces
}

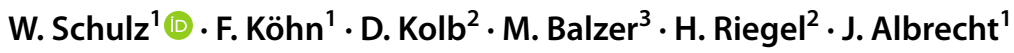

Received: 2 August 2021 / Accepted: 6 October 2021 / Published online: 15 October 2021

(c) The Author(s) 2021

\begin{abstract}
This study considers anisotropic microstructures with typical dimensions of a few $10 \mu \mathrm{m}$ which have been created on steel surfaces by laser surface texturing (LST). It is shown that the subsequent deposition of thin molybdenum nitride coatings by high-power impulse magnetron sputtering (HiPIMS) leads to surfaces that conserve the surface microstructures and exhibit a remarkably large resistance against mechanical wear. Tribological experiments with steel counter bodies are substantially influenced by the relative orientation of the structures and the wear track. Both friction and wear are shown to be modified by more than $30 \%$, with the main effect being the removal of abrasion particles from the mechanical contact. Experiments with alumina counter bodies that hardly provide wear particles show that the orientation has no effect on the abrasion of the counter body. The novelty of the article lies in the combination of MoN coatings with surface texturing.
\end{abstract}

Keywords Molybdenum nitride $\cdot$ Friction $\cdot$ Wear $\cdot$ Laser surface texturing (LST) $\cdot$ Tribology

\section{Introduction}

The protection of metallic surfaces against mechanical wear is frequently realized by the deposition of thin films of transition metal nitrides. In particular, titanium nitride (TiN) and titanium aluminum nitride (TiAlN) are typical materials used for industrial applications facing large mechanical forces. Recently, there has been a growing interest in using molybdenum nitride (MoN), see [1-3]. The reason for this is obvious: MoN possesses very high hardness and, in particular, resistance properties against high temperatures above $250{ }^{\circ} \mathrm{C}$. Since the formation of stoichiometric phases in the molybdenum-nitrogen system requires a deposition process far from thermal equilibrium, high-power impulse magnetron sputtering (HiPIMS) [4], arc plasma-assisted deposition

W. Schulz

wadim.schulz@hs-aalen.de

1 Research Institute of Innovative Surfaces FINO, Aalen University, Beethovenstr. 1, 73430 Aalen, Germany

2 LaserApplicationCenter LAZ, Aalen University, Beethovenstr. 1, 73430 Aalen, Germany

3 Department of Plasma Surface Technology and Materials Physics, Research Institute for Precious Metals and Metal Chemistry fem, Katharinenstr. 17, 73525 Schwäbisch Gmünd, Germany
[5], or pulsed laser deposition (PLD) [6] are typically used for the coating process.

A further increase of the wear resistance for hard surfaces can be obtained through the introduction of microstructures into the surface. In particular, this is found to be useful in the case of dry contacts [7]. There are various methods of producing suitable surfaces to reduce their friction properties. Shimizu et al. structured brass surfaces with vibration-assisted microcutting [8]. Various micro-/ nanoscale geometries can be produced by a single crystal diamond tool through elliptical vibration cutting [9]. Sube et al. have created microimprints on the surface by mechanical embossing using a diamond stamp, significantly reducing friction against steel [10]. It has been shown that a modification of the surface topography on a length scale of several ten micrometers prepared by laser structuring or mechanical imprinting can efficiently reduce friction and wear. The introduction of microstructures in dry frictional contacts can lead to a reduction of the coefficient of friction [11-13]. By adding a solid lubricant in combination with a surface structure a significant reduction in the coefficient of friction can be achieved as well [14]. The properties of hard coatings which already have inherently good wear protection properties can also be optimized by applying a surface structure [15]. Amanov et al. showed that the structured surfaces do not necessarily have to be flat but the presence of bulges 
can also lead to a reduction in friction [16]. In addition to dry frictional contacts many applications require the use of a liquid lubricant. A surface structure can increase the residence time of the lubricant in the contact area leading to a decrease of friction and wear [17, 18]. By structuring the counter bodies, it was also shown that the coefficient of friction can be reduced [19].

Recent studies provide a useful overview of surface structuring processes by laser-based techniques and the combination of coatings and texturing [20,21]. In the case of abrasion-dominated wear mechanisms, the main role is to capture wear debris inside the structures to remove it from the mechanical contact. Kumar et al. showed that by microstructuring the surface, abrasion particles are trapped and wear is reduced [22]. Furthermore, Kommer et al. found that the combination of structuring of the surface with subsequent deposition of a hard material layer additionally reduces wear. In addition, accumulating material inside the microimprints during wear tests has been identified to be originated by the steel counter body [4].

In this work we consider anisotropic, line-like surface structures that are created by laser structuring in steel surfaces before coating with molybdenum nitride. Since both friction and wear result from forces with predefined orientation, it is reasonable to use unidirectional structures for our purposes. Analyzing carefully the consequences of the local orientation of the microstructures may offer a way toward surfaces with tailored properties of friction and wear. Similar surface modifications have been considered by Rosenkranz et al. for the investigation of steel/steel contacts [11]. It was found that wear debris are substantial for the description of friction and wear. Further it was shown that distribution and kinetics of wear debris were strongly affected by the relative orientation of the structures and the wear track. In addition, a systematic analysis of the orientation dependence of friction and wear of the surface structures was performed. This approach is extended to nitride-coated surfaces in this work. The results of Rosenkranz et al. support the idea that capturing and guiding abrasion particles provided by the counter body can significantly control friction and wear at MoN surfaces against steel.

\section{Experimental Details}

We use small blocks made of high-speed steel (DIN 1.3343) with dimensions of $20 \times 12 \times 3 \mathrm{~mm}^{3}$. The surface has been ground and polished using standard preparation methods to achieve a final roughness of $R_{\mathrm{a}}=5 \mathrm{~nm}$. The line structures have been produced using a near-infrared TRUMPF TruMark 5020 short-pulsed marking laser with a wavelength of $1062 \mathrm{~nm} \pm 3 \mathrm{~nm}$, integrated in a TRUMPF TruMark Station 5000. The focal diameter of approx. $45 \mu \mathrm{m}$ was set on the samples surface. The feed rate of the laser was $800 \mathrm{~mm} / \mathrm{s}$ at an average laser power of $20.5 \mathrm{~W}$, a pulse repetition rate of $80 \mathrm{kHz}$, and a pulse duration of $200 \mathrm{~ns}$. This results in a pulse overlap of about $77.8 \%$ and a single pulse energy of approx. $0.256 \mathrm{~mJ}$. The line spacing has been chosen to be $100 \mu \mathrm{m}$. Laser crossing was carried out twice at each surface to ensure an appropriate aspect ratio of the line structures. Subsequently, the samples are again subjected to a gentle polishing process to remove the accumulated material along the line edges to obtain sharp edges. After polishing, the specimens undergo ultrasonic cleaning in an acetone bath for $10 \mathrm{~min}$.

The MoN coatings were deposited by reactive highpower impulse magnetron sputtering (HiPIMS) using a 3" sputtering cathode with a Mo-target (purity 99.95 at.\%) as suggested by Kommer et al. [4]. The process parameters were chosen to realize a pure $\delta$-MoN coating: HiPIMSPulse pattern: $t_{\text {on }}=14 \mu \mathrm{s}, T=2000 \mu \mathrm{s}, p\left(\mathrm{~N}_{2}\right)=0.4 \mathrm{~Pa}$, and $p\left(\mathrm{Ar}+\mathrm{N}_{2}\right)=0.6 \mathrm{~Pa}$. No external substrate bias voltage has been applied. The coating thickness was about $1.8 \mu \mathrm{m}$ as measured by tactile profilometry on a coating step gained by covering a part of the substrate with a razor blade segment. The indentation hardness was $H_{\mathrm{IT}}$ $(0.009 / 10 / 10 / 10)=32 \pm 2 \mathrm{GPa}$ (Fischer H100 xy p).

The topography of the surfaces before and after deposition of the nitride layers is mapped by white-light interferometry and light microscopy, as depicted in Fig. 1.

Panels (A) and (B) show images, respectively, of a linearly structured surface before deposition and after. In addition, a corresponding horizontal profile is depicted below. It is seen readily that the PVD process basically conserves the prepared laser structure after deposition. Both images

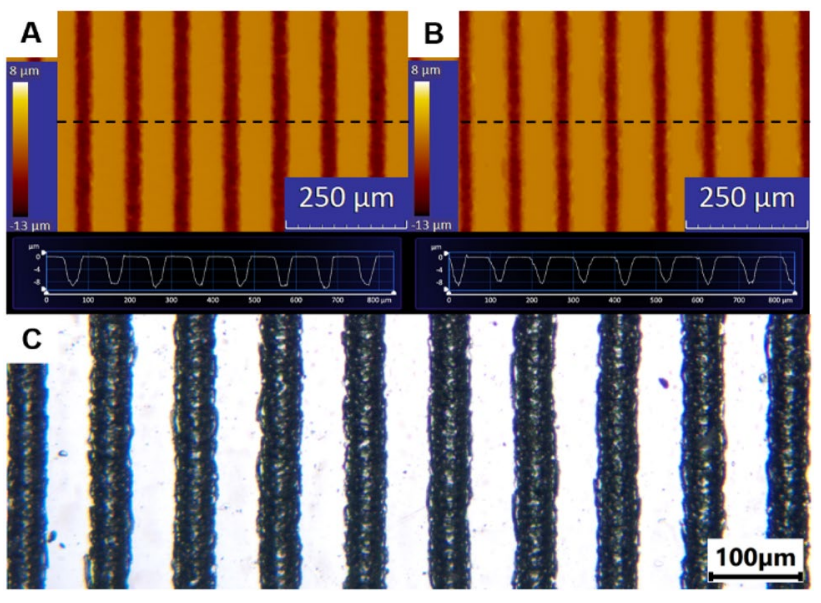

Fig. 1 Surface topography of line-like surface structure obtained by Laser patterning. The results are obtained by white-light interferometry before (A) and after (B) the deposition of MoN. The profiles below are extracted along the horizontal dashed lines. C Optical micrograph of the surface after coating 
show a highly regular structure of parallel lines with an individual width of about $40-45 \mu \mathrm{m}$ and a depth of $8-9 \mu \mathrm{m}$, which correspond to an aspect ratio of 5:1. The generated abrasion particles are in the micrometer range, so the structures must be larger than the diameter of the particles. A line spacing of $100 \mu \mathrm{m}$ with a track width of $40 \mu \mathrm{m}$ means that the unstructured portion of the surface predominates. It is made sure, however, that sufficient structure is available to remove accumulating particles from the frictional contact. However, a closer look reveals that both width and depth of the created linear structures are slightly reduced by about $10 \%$ after deposition. Since the depth of the laser structures is significantly larger than the film thickness of the MoN layer, this does not affect further conclusions of this work.

Additional information is gained from the optical micrograph $(\mathrm{C})$ that is depicted below. Here, it is seen that the lines of removed material exhibit an irregular microstructure pattern that is essentially due to the laser preparation process in pulse mode. The surface areas in between the structured regions remain basically unmodified, indicating that those parts of the surface which are in mechanical contact with a counter body are hardly modified.

To access the required tribological information, namely friction and wear, all structured and coated surfaces were characterized thoroughly by the oscillation tribometer SRV3 from Optimol Instruments. The set-up is equipped with 100Cr6 (Hardness 6.9 GPa) and $\mathrm{Al}_{2} \mathrm{O}_{3}$ (Hardness 16.7 GPa) balls as counter bodies with a diameter of $10 \mathrm{~mm}$ are pressed onto the surface using a load of $F_{\mathrm{N}}=20 \mathrm{~N}$. For the case of a steel ball on a flat MoN surface, we can calculate the Hertzian pressure to be $p_{\mathrm{H}}=900 \mathrm{MPa}$. However, in the case of the microstructured surface the usefulness of this value is somewhat disqualified. During all measurements a stroke length of $1 \mathrm{~mm}$, a frequency of $2 \mathrm{~Hz}$, and a temperature $T=50^{\circ} \mathrm{C}$ are used. The experiments were performed under slight heating, keeping the interference due to variations in room temperature at a minimum level. Small variations in air humidity of $55 \pm 5 \%$ are considered to be negligible. The exposure duration has been $t=900 \mathrm{~s}$ in each case. After mechanical treatment, the shape, width, and volume of the wear track are analyzed using white-light interferometry.

\section{Results}

First, the coefficients of friction are measured against steel counter bodies under dry conditions. In particular, the relative orientation of surface pattern and wear track is varied systematically. To ensure reproducibility, each test is performed three times. In Fig. 2 the averaged curves from the tests are plotted, providing the friction coefficients obtained under relative angles of $0^{\circ}$ to $90^{\circ}$ in steps of $22.5^{\circ}$.

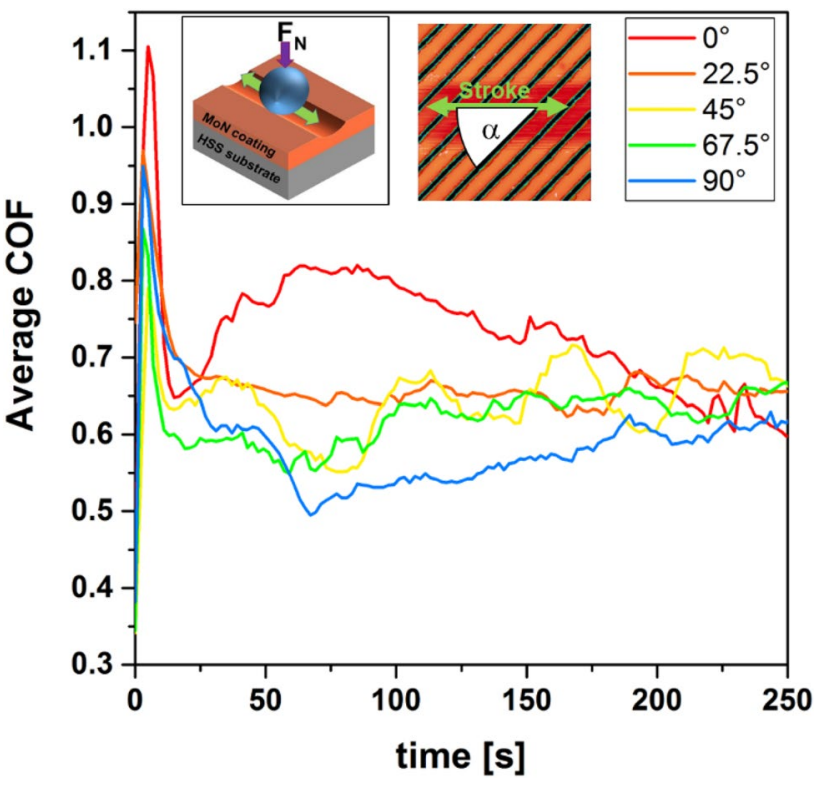

Fig. 2 Average coefficients of friction (COF) with a 100Cr6 counter body against a structured MoN coating up to $250 \mathrm{~s}$. Inset left: schematic representation of the tribological stress. Inset center: determination of the angles in relation to the loading direction

Inset 1 (top left) illustrates, schematically, the mechanical stress during the tribometry testing. Here, a spherical counter body is guided over the surface in oscillating motion subjected to no lubricant. The definition of the angle $\alpha$ is found in Inset 2 (center). If $\alpha=0^{\circ}$ the wear track is parallel to the line-like structures and for $\alpha=90^{\circ}$ the structures are perpendicular to the direction of motion of the counter body. For a set of predefined angles, the orientation is fixed in the structuring process, with no rotation of the samples allowed during testing.

The results of the friction experiments are shown as colored curves over a time period of $t=250 \mathrm{~s}$. Different colors refer to different angles. In a short time period, initially, of about $t=25 \mathrm{~s}$ the transient behavior is observed. Owing to the complex surface geometry, this behavioral pattern cannot be assigned directly to any of the basic cases reported in [23]. A reasonably detailed description would require, e.g., the exact position of the spherical counter body on top of the structured surface, but this is not within the scope of this paper. After $t=25 \mathrm{~s}$ we find a systematic decrease of the COF with increasing values of $\alpha$. The strongest effect is found around $t=75 \mathrm{~s}$ where a large COF of $\mu=0.82$ is found for an angle of $\alpha=0^{\circ}$, steadily decreasing to $\mu=0.49$ in the case of the $90^{\circ}$ geometry. After $t=75 \mathrm{~s}$ the difference between the individual curves gradually decreases in the time interval up to $t=225 \mathrm{~s}$. Shortly after, no significant difference between the individual COF curves can be detected. 
In order to determine the wear volume of layer and counter body the wear tracks have been characterized using white-light interferometry. An overview of the results is depicted in Fig. 3.

Figure 3 shows interferometry images of the wear tracks occurring in the individual-structured surfaces $\left(\alpha=0^{\circ}-90^{\circ}\right)$ after tribological characterization over $t=900 \mathrm{~s}$. The laser structures introduced are clearly visible as dark parallel lines. The top row depicts the cases of parallel and perpendicular orientation: $\alpha=90^{\circ}$ (top left) and $\alpha=0^{\circ}$ (top right). Below, the wear tracks of the angles $\alpha=67.5^{\circ}$ (bottom left), $\alpha=45^{\circ}$ (bottom center), and $\alpha=22.5^{\circ}$ (bottom right) are shown. The depth information is shown by the color scaling in the color bar at the center, with a spectrum from 0.3 (white) to $-6 \mu \mathrm{m}$ (black). All images allow the identification of the wear track that is seen as red stripe with horizontal orientation. In all cases a width of about $250 \mu \mathrm{m}$ is found; however, it decreases slightly from $90^{\circ}$ to $0^{\circ}$ by roughly $10 \%$.

Information about depth can also be extracted from the interferometry images. As an example, the profile depicted below is extracted from the yellow box in the top left panel

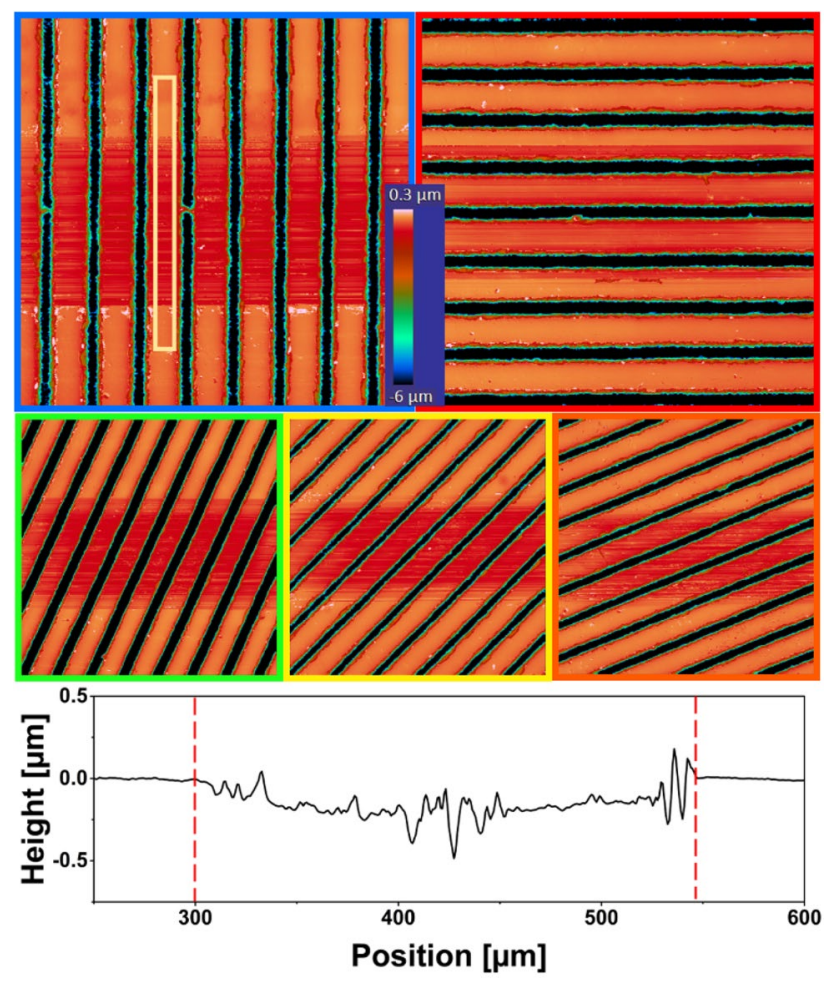

Fig. 3 Profilometric images after tribological characterization. The top row depicts parallel and perpendicular orientation: $90^{\circ}$ (left, blue); $0^{\circ}$ (right, red). The second row depicts the angles in between: green box: $67.5^{\circ}$ (left, green); $45^{\circ}$ (center, yellow); $22.5^{\circ}$ (right, orange). The profile below is extracted from the marked box in the top left image. Vertically oriented, dashed lines mark the width of the wear track (Color figure online) of Fig. 3. Here, a wear track with basically spherical shape is found exhibiting a width of $250 \mu \mathrm{m}$. In addition, the profile is not smooth. There are individual narrow wear scars with a typical width of about $10 \mu \mathrm{m}$ and a depth of several $100 \mathrm{~nm}$. We find a maximum depth of the wear profile of about $0.5 \mu \mathrm{m}$, clearly indicating that wear is restricted to the MoN layer with a thickness of $1.8 \mu \mathrm{m}$.

To determine the wear volume in the MoN film, the analysis uses an averaged profile perpendicular to the wear track. Then the surface fraction has to be considered that has been removed during laser structuring and where no material has been removed.

A rather unusual procedure has to be used for the $0^{\circ}$ geometry. Here, an averaged profile does not provide the correct shape for the wear track. The missing volume has to be extracted individually from each area between the laser lines, as depicted in Fig. 4.

An exception is the structure at $\alpha=0^{\circ}$. Owing to the parallel direction of motion, material removal occurs only at some individual ridges between the laser lines, as shown in Fig. 4A. Here, the missing volume has to be determined locally at these ridges. Therefore, a rectangular surface topography has been assumed, leading to some enlarged error bars in the final evaluation. The performed process is shown schematically in Fig. 4B.

Wear volume occurring at the ball-shaped counter body has been extracted geometrically. The diameter of the flat and circular-shaped wear region has been extracted. The wear volume is then calculated as the volume of the missing ball cap. In the case of the $0^{\circ}$ result, the wear volume cannot be described by a spherical cap due to the reasons mentioned above. Again, a local investigation has to be performed ending in values with larger error bars. A sum of the determined wear volumes is depicted in Fig. 5. For comparison, values for the $\mathrm{COF}$ are added that are extracted from Fig. 2 by averaging between $t=25 \mathrm{~s}$ and $t=225 \mathrm{~s}$.

By changing the orientation of the structures to higher angles the wear volume also increases. In the case of the

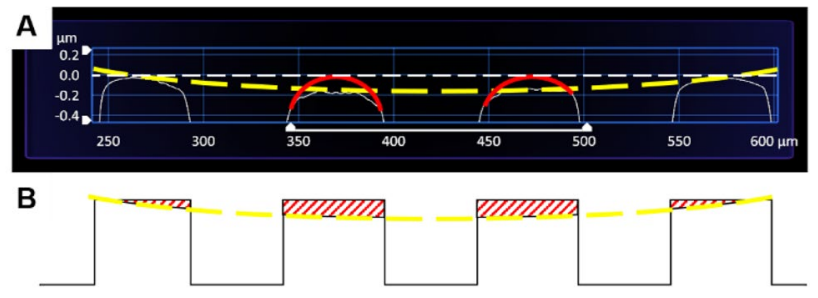

Fig. 4 Original wear profile at $\alpha=0^{\circ}$ as measured (A). The whitedashed line marks the surface before the testing. The yellow-dashed line shows the spherical wear track; the red ball caps indicate the areas where material is removed. Schematic representation of the profile for better determination of the wear volume (B) (Color figure online) 


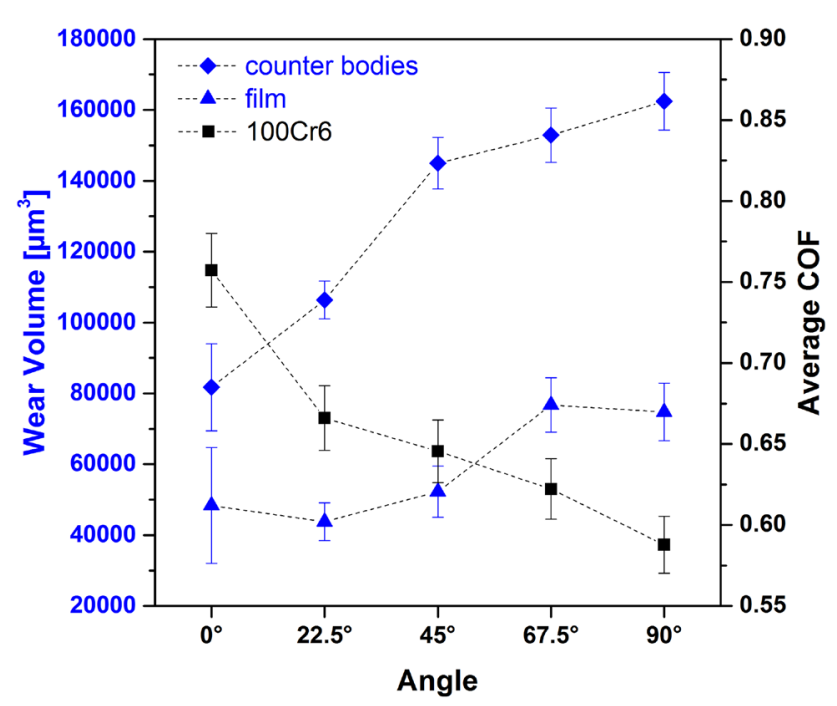

Fig. 5 Angular dependence of the wear volumes of the MoN layer and the counter body (blue). Average coefficients of friction (black) (Color figure online)

MoN film (blue triangles) wear volumes in the range $40,000 \mu^{3}$ to $75,000 \mu \mathrm{m}^{3}$ are found. A similar behavior shows the wear volume of the counter body (blue diamonds). Here the values are between $80,000 \mu^{3}$ and $160,000 \mu^{3}$. The wear of the counter bodies is approx. $100 \%$ higher compared to the microstructured hard coating. The black squares describe the average coefficient of friction in the time interval $t=25 \mathrm{~s}$ to $t=225 \mathrm{~s}$, which have been extracted from the friction curves shown in Fig. 2. It is observed that an increase of the angle of the structures leads to a decrease of the coefficient of friction.

Owing to the large wear of the counter body it is assumed that the observed damage is caused to a large extent by third particles originating from the $100 \mathrm{Cr} 6$ steel counter body. These particles are notably responsible for friction and wear. The observed systematic influence of line-like surface structures is closely related to the behavior of these particles inside the tribological contact.

To verify this assumption, we perform an experiment using an $\mathrm{Al}_{2} \mathrm{O}_{3}$ counter body that exhibits a significantly higher wear resistance and thus provides hardly any abrasion particles. Using the same parameters as for the results in Fig. 2 we obtain the friction curves depicted in Fig. 6.

For the curves in Fig. 6 the same color code has been used as for those in Fig. 2. Here, a significant difference compared with the results of Fig. 2 is observed. All friction curves basically show the same behavior. After the initial time period up to $t=25 \mathrm{~s}$ all curves depart from coefficient of friction values of $\mu=0.50-0.55$. During the measurement period of $250 \mathrm{~s}$ a slight increase up to values of $\mu=0.55-0.60$ is observed. No systematic dependence

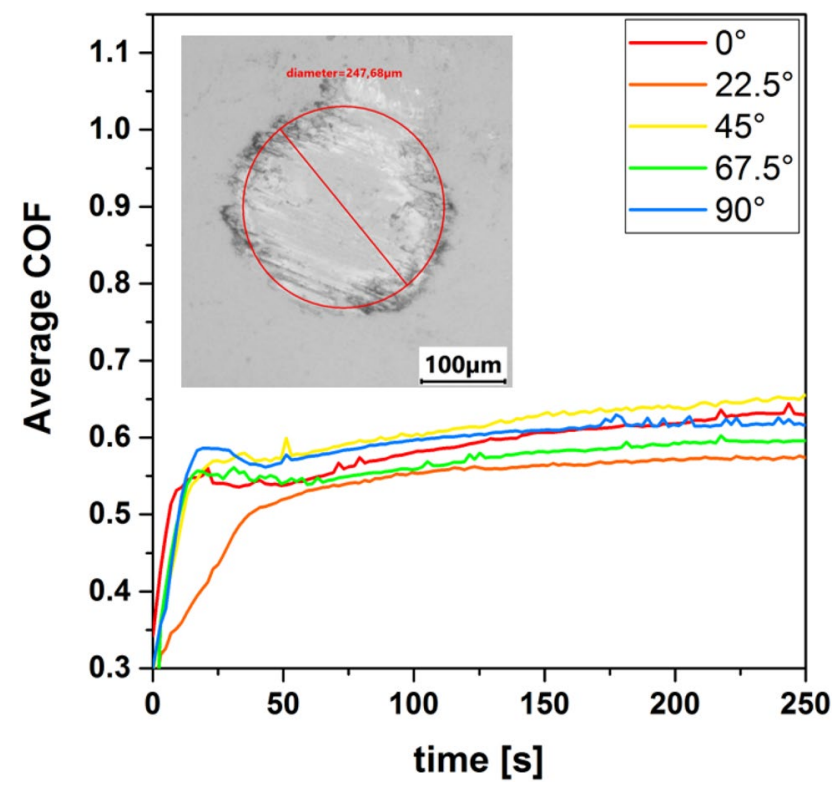

Fig. 6 Coefficients of friction with $\mathrm{Al}_{2} \mathrm{O}_{3}$ counter body against a structured MoN coating up to $250 \mathrm{~s}$ under equivalent conditions as used for Fig. 2. Inset: optical micrograph of an $\mathrm{Al}_{2} \mathrm{O}_{3}$ counter body after the tribological test

can be found when varying the orientation of the microstructures. This is in clear contrast to the experiments using a $100 \mathrm{Cr} 6$ counter body.

For a more detailed analysis of these friction results, we summarize the average coefficients of friction obtained for $100 \mathrm{Cr} 6$ and $\mathrm{Al}_{2} \mathrm{O}_{3}$ counter bodies in Fig. 7.

While the black curve refers to the $100 \mathrm{Cr} 6$ counter bodies, the red curve refers to $\mathrm{Al}_{2} \mathrm{O}_{3}$. As already described, a decrease of the friction values with increasing angle against the steel counter body can be observed. The friction in the case of motion parallel to the laser lines exhibits a maximum at $\mu=0.76$, the smallest value with $\mu=0.59$ is found for the perpendicular orientation. Changing the set-up to an $\mathrm{Al}_{2} \mathrm{O}_{3}$ counter body, the friction values range from $\mu=0.53-0.60$ and no systematic dependence can be extracted. In addition, the coefficient of friction values for unstructured and microimprinted MoN-coated surfaces versus $100 \mathrm{Cr} 6$ are added to the diagram as dashed lines. The upper-dashed line describes friction values for a similar surface without structure. Average friction values of approx. $\mu=0.85$ are achieved here. It should be noted that a similar experiment was carried out by Sube et al. who used a stamp to structure the sample surface. A MoN layer was then deposited and the surface tribologically characterized [10]. The average coefficient of friction against a $100 \mathrm{Cr} 6$ counter body was also approx. $\mu=0.65$, as shown by the lower-dashed line in Fig. 7.

The different behavior of the friction curves for both counter bodies shows that the systematic influence of orientation is related to the occurrence of abrasion particles. By 


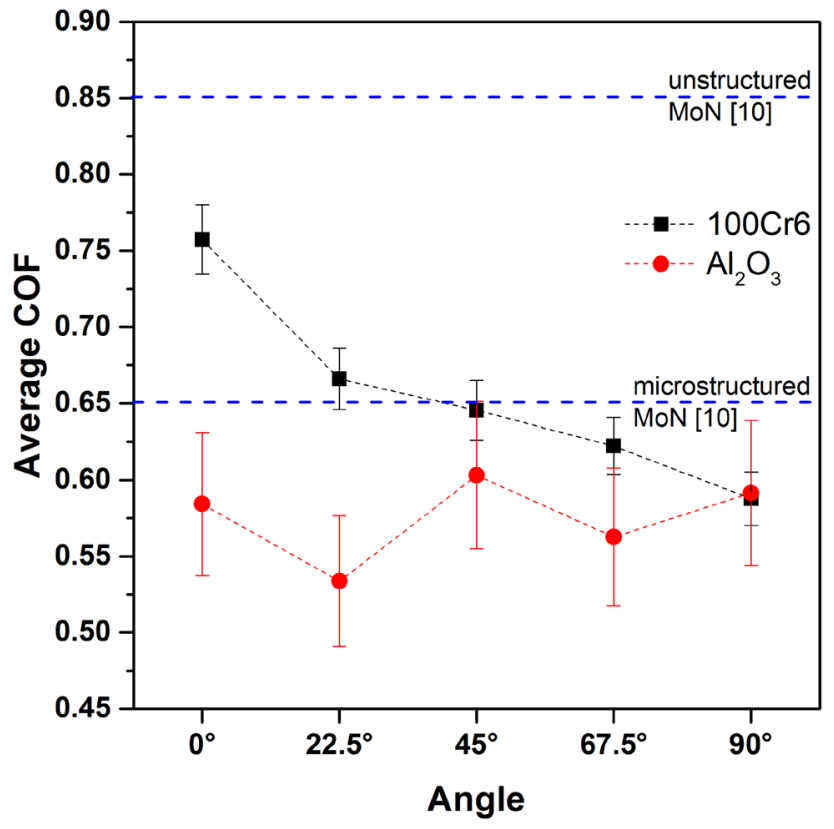

Fig. 7 Coefficients of friction of $100 \mathrm{Cr} 6$ (black) and $\mathrm{Al}_{2} \mathrm{O}_{3}$ (red) counter bodies against MoN as a function of the angle of the microstructures. For reference: unstructured MoN-coated surface (upperdashed line) and microimprinted MoN-coated surface (lower-dashed line) versus 100Cr6 counter bodies [10] (Color figure online)

determining the abrasion volume after mechanical testing at the counter bodies by interferometry, it is found that the steel counter bodies exhibit an average wear volume of the order of $100,000 \mu^{3}$. In the case of alumina values of approx. $2,000 \mu^{3}$ are found. This means that the number of abrasion particles is drastically reduced in the $\mathrm{Al}_{2} \mathrm{O}_{3}$ contact.

\section{Discussion}

It is well known that under certain circumstances surface structures are able to remove third particles out of the frictional contact and decrease friction and wear. Kumar et al. created structures on uncoated 100Cr6 steel surfaces by laser processing and characterized them with respect to friction and wear. In doing so they were able to remove third bodies from the tribological system by trapping them inside the cavities. The structure alone led to a reduction in the coefficient of friction from approx. $\mu=0.70$ to approx. $\mu=0.55$ [22]. Sube et al. showed that it is possible to significantly reduce friction by combining surface structuring and a hard material layer. In their work, a reduction of the coefficient of friction by approx. $25 \%$ was reported (see blue-dashed lines in Fig. 7) [10].

The results presented in this paper confirm the impact of structured surfaces on friction and wear. The results are quite remarkable in that completely identical surfaces have been examined, differing only in the orientation of the introduced structures. The particles generated are trapped in the linelike structures and do not contribute to the frictional contact. The orientation of the lines is critical. The highest coefficient of friction has been observed for the case of parallel orientation $\left(\alpha=0^{\circ}\right)$, as shown in Fig. 2. A stepwise reorientation of the structure ensured a reduction of the observed COF down to a value of $\mu=0.60$. Comparing the line structures with the structured surface of Sube et al., it has been shown that equivalent coefficients of friction are obtained at an orientation of $\alpha=45^{\circ}$ already, see Fig. 7. With a perpendicular orientation $\left(\alpha=90^{\circ}\right)$ the effect could be increased by further $10 \%$.

As already observed by Kumar et al. the effect of particle trapping is limited in time. Due to the relatively large surface stress and the absence of a lubricant in the tribological contact, the structures are repeatedly clogged or-in the worst case - completely abraded [22]. The same behavior has been observed in the experiments reported here. Although the tribological tests, individually, had a total duration of $900 \mathrm{~s}$, the friction values from Fig. 2 reached a similar plateau after only $225 \mathrm{~s}$. This suggests that from this point on, the structures are clogged with particles and the positive effect is no longer effective. Topographic investigations confirm this assumption. It is observed that inside the wear track the line structures were clogged with particles. All data points after $\mathrm{t}=225 \mathrm{~s}$ have been omitted for the analysis.

Since the wear volume is directly related to the presence of abrasive particles, the wear on the respective surfaces has been examined in more detail. The lowest volumes are achieved with a structure orientation below $\alpha=45^{\circ}$.

The steel counter body moves along the structure in the case of $\alpha=0^{\circ}$ orientation, similar to rails. The effective area for generating abrasion particles is smaller than that for the other surface structures. In addition, the abrasion of the counter body leads to a grooved surface where the remaining parts fit into the lines of the MoN film. This increases the mechanical contact area and the role of particles. Thus, the coefficient of friction increases.

Within the structure the particles are transported out of the wear track by the relatively high shear forces, until they become anchored in the structure by mechanical interlocking and level the structure.

The situation is similar at $\alpha=45^{\circ}$. Here, the wear volume is at a similar level as for smaller angles. Significantly higher wear volumes were observed for orientations above $\alpha=45^{\circ}$. Up to $100 \%$ more coating material was removed than at small angles.

The same investigations were carried out on the steel counter bodies. Here, the direct influence of the structure in the abrasion volume can be seen. With a parallel structure alignment $\left(\alpha=0^{\circ}\right)$ in relation to the direction of motion, rather small abrasion takes place on the counter 


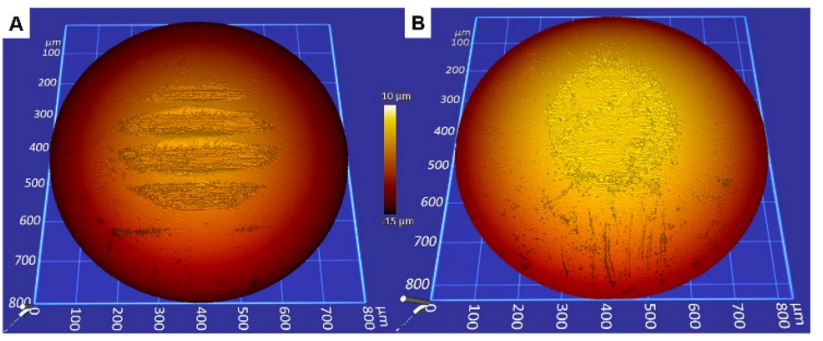

Fig. 8 White-light interferometric images of 100Cr6 counter bodies after tribological loading. A Wear with the structures oriented parallel $\left(\alpha=0^{\circ}\right)$ to the direction of motion. B Wear with structure orientations $\left(\alpha>0^{\circ}\right)$

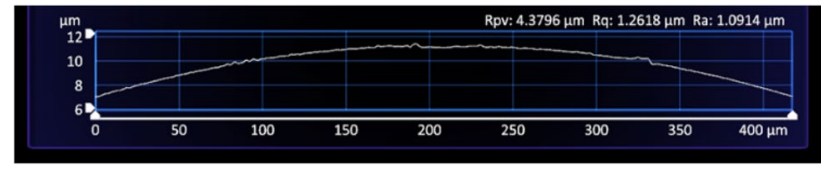

Fig. 9 Surface profile of an $\mathrm{Al}_{2} \mathrm{O}_{3}$ counter body after tribological testing

bodies. This is justified in the comparatively small area of contact between the friction partners, leading to a striking wear pattern on the counter bodies, as shown in Fig. 8A. As an example, the removal at all other angles is shown in Fig. 8B. It is seen that a flat surface has evolved at the end of the testing period. Changing the orientation to larger angles, the erosion increases up to a value of $160,000 \mu \mathrm{m}^{3}$, which corresponds to an increase in wear of about $100 \%$. The relatively sharp edges of the structures lead to an effect similar to the machining of metals. Individual layers are scraped off the counter bodies during each cycle resulting in the damage patterns shown. This effect increases with increasing angle of the surface structures.

For comparison, counter bodies made of $\mathrm{Al}_{2} \mathrm{O}_{3}$ have been used to confirm the influence of particle trapping. The friction curves depicted in Fig. 6 show an almost identical course from a duration of about $30 \mathrm{~s}$ onward. A comparison of the ceramic and steel counter bodies shows that the friction values of $\mathrm{Al}_{2} \mathrm{O}_{3}$ range from $\mu=0.53-0.60$ and are thus generally lower. Here, the influence of the structure seems to be only marginal. The surface of the $\mathrm{Al}_{2} \mathrm{O}_{3}$ counter bodies has been characterized after testing using a white-light interferometer. It is found that hardly any abrasion takes place on the counter bodies, as can be seen in Fig. 9.

\section{Conclusion}

Wear-resistive surfaces with anisotropic line-like microstructures are produced in a two-step process. First, laser patterning is used to create regular microgrooves into a steel surface. Then, the steel surfaces are coated with MoN by HiPIMS. It is shown that the structures introduced provide an effective means of controlling friction and wear for such surfaces. A change of the relative angle of structures and motion leads to a systematic change of friction and wear. In particular, it enables one to remove friction particles from the tribological contact and thus reduces the coefficient of friction. Indeed, this is most successful if the line structures are orientated perpendicularly relative the load direction. A comparison with microembossed surfaces from [10] shows that the structures used here, up to suitable orientation, enable a reduction in the coefficient of friction which has not been achieved so far. A comparison with $\mathrm{Al}_{2} \mathrm{O}_{3}$ counter bodies shows that the underlying mechanism is the trapping of the abrasion particles of the counter bodies.

Acknowledgements The authors would like to thank Gaby KetzerRaichle and Elvira Reiter of the Institute for Materials Research Aalen (IMFAA) for their active support in the preparation of the specimens and Mahyar Mahinzaeim for fruitful discussions.

Funding Open Access funding enabled and organized by Projekt DEAL.

Open Access This article is licensed under a Creative Commons Attribution 4.0 International License, which permits use, sharing, adaptation, distribution and reproduction in any medium or format, as long as you give appropriate credit to the original author(s) and the source, provide a link to the Creative Commons licence, and indicate if changes were made. The images or other third party material in this article are included in the article's Creative Commons licence, unless indicated otherwise in a credit line to the material. If material is not included in the article's Creative Commons licence and your intended use is not permitted by statutory regulation or exceeds the permitted use, you will need to obtain permission directly from the copyright holder. To view a copy of this licence, visit http://creativecommons.org/licenses/by/4.0/.

\section{References}

1. Gassner, G., Mayrhofer, P.H., Kutschej, K., Mitterer, C., Kathrein, M.: Magnéli phase formation of PVD Mo-N and W-N coatings. Surf. Coat. Technol. (2006). https://doi.org/10.1016/j.surfcoat. 2006.07.067

2. Suszko, T., Gulbiński, W., Jagielski, J.: The role of surface oxidation in friction processes on molybdenum nitride thin films. Surf. Coat. Technol. (2005). https://doi.org/10.1016/j.surfcoat.2004.07. 119

3. Koshy, R.A., Graham, M.E., Marks, L.D.: Synthesis and characterization of $\mathrm{CrN} / \mathrm{Mo}_{2} \mathrm{~N}$ multilayers and phases of molybdenum nitride. Surf. Coat. Technol. (2007). https://doi.org/10.1016/j. surfcoat.2007.07.090

4. Kommer, M., Sube, T., Richter, A., Fenker, M., Schulz, W., Hader, B., Albrecht, J.: Enhanced wear resistance of molybdenum nitride coatings deposited by high power impulse magnetron sputtering by using micropatterned surfaces. Surf. Coat. Technol. (2018). https://doi.org/10.1016/j.surfcoat.2017.10.071

5. Krysina, O.V., Ivanov, Yu.F., Koval, N.N., Prokopenko, N.A., Shugurov, V.V., Petrikova, E.A., Tolkachev, O.S.: Composition, 
structure and properties of Mo-N coatings formed by the method of vacuum-arc plasma-assisted deposition. Surf. Coat. Technol. (2021). https://doi.org/10.1016/j.surfcoat.2021.127153

6. Bereznai, M., Tóth, Z., Caricato, A.P., Fernández, M., Luches, A., Majni, G., Mengucci, P., Nagy, M., Juhász, A., Nánai, L.: Reactive pulsed laser deposition of thin molybdenum- and tungsten-nitride films. Thin Solid Films (2005). https://doi.org/10.1016/j.tsf.2004. 06.149

7. Gachot, C., Rosenkranz, A., Reinert, L., Ramos-Moore, E., Souza, N., Müser, M.H., Mücklich, F.: Dry friction between laser-patterned surfaces: role of alignment, structural wavelength and surface chemistry. Tribol. Lett. (2013). https://doi.org/10.1007/ s11249-012-0057-y

8. Shimizu, J., Nakayama, T., Watanabe, K., Yamamoto, T., Onuki, T., Ojima, H., Zhou, L.: Friction characteristics of mechanically microtextured metal surface in dry sliding. Tribol. Int. (2020). https://doi.org/10.1016/j.triboint.2019.02.042

9. Zhang, J., Zhang, J., Rosenkranz, A., Suzuki, N., Shamoto, E.: Frictional properties of surface textures fabricated on hardened steel by elliptical vibration diamond cutting. Precis. Eng. (2019). https://doi.org/10.1016/j.precisioneng.2019.06.001

10. Sube, T., Kommer, M., Fenker, M., Hader, B., Albrecht, J.: Reduced friction on $\gamma-\mathrm{Mo} 2 \mathrm{~N}$ coatings deposited by high power impulse magnetron sputtering on microstructured surfaces. Tribol. Int. (2017). https://doi.org/10.1016/j.triboint.2016.10.028

11. Rosenkranz, A., Reinert, L., Gachot, C., Mücklich, F.: Alignment and wear debris effects between laser-patterned steel surfaces under dry sliding conditions. Wear (2014). https://doi.org/10. 1016/j.wear.2014.06.016

12. Bathe, R., Sai Krishna, V., Nikumb, S.K., Padmanabham, G.: Laser surface texturing of gray cast iron for improving tribological behavior. Appl. Phys. A (2014). https://doi.org/10.1007/ s00339-014-8281-y

13. Higuera-Garrido, A., González, R., Cadenas, M., Viesca, J. L., Hernández-Battez, A.: Microstructure of NiCrBSi laser cladding coatings textured by ND-YAG laser. Proceeding of the ASME/ STLE 2011 International Joint Tribology Conference 61088 (2011)

14. Oksanen, J., Hakala, T.J., Tervakangas, S., Laakso, P., Kilpi, L., Ronkainen, H., Koskinen, J.: Tribological properties of laser-textured and ta-C coated surfaces. Tribol. Int. (2014). https:// doi.org/10.1016/j.triboint.2013.09.005

15. Gachot, C., Grützmacher, P., Rosenkranz, A.: Laser surface texturing of TiAl multilayer films - effects of microstructure and topography on friction and wear. Lubricants (2018). https://doi.org/10. 3390/lubricants6020036

16. Amanov, A., Tsuboi, R., Oe, H., Sasaki, S.: The influence of bulges produced by laser surface texturing on the sliding friction and wear behavior. Tribol. Int. (2013). https://doi.org/10.1016/j. triboint.2012.10.018

17. Andersson, P., Koskinen, J., Varjus, S., Gerbig, Y., Haefke, H., Georgiou, S., Zhmud, B., Buss, W.: Microlubrication effect by laser-textured steel surfaces. Wear (2007). https://doi.org/10. 1016/j.wear.2006.06.003

18. Stark, T., Alamri, S., Aguilar-Morales, A.I., Kiedrowski, T., Lasagni, A.F.: Positive effect of laser structured surfaces on tribological performance. J. Laser. Micro. Nanoeng. (2019). https://doi. org/10.2961/jlmn.2019.01.0003

19. Fiaschi, G., Di Lauro, M., Ballestrazzi, A., Rota, A., Biscarini, F., Valeri, S.: Tribological response of laser-textured steel pins with low-dimensional micrometric patterns. Tribol. Int. (2020). https:// doi.org/10.1016/j.triboint.2019.01.007

20. Kumar, V., Verma, R., Kango, S., Sharma, V.S.: Recent progresses and applications in laser-based surface texturing systems. Mater. Today Commun. (2021). https://doi.org/10.1016/j.mtcomm.2020. 101736

21. Rosenkranz, A., Costa, H.L., Baykara, M.Z., Martini, A.: Synergetic effects of surface texturing and solid lubricants to tailor friction and wear-a review. Tribol. Int. (2021). https://doi.org/10. 1016/j.triboint.2020.106792

22. Kumar, M., Ranjan, V., Tyagi, R.: Effect of shape, density, and an array of dimples on the friction and wear performance of laser textured bearing steel under dry sliding. J. Mater. Eng. Perform. (2020). https://doi.org/10.1007/s11665-020-04816-8

23. Blau, P.J.: On the nature of running-in. Tribol. Int. (2005). https:// doi.org/10.1016/j.triboint.2005.07.020

Publisher's Note Springer Nature remains neutral with regard to jurisdictional claims in published maps and institutional affiliations. 